\title{
A FLY THAT MIMICS JUMPING SPIDERS*
}

\author{
BY ThOMAS EISNER \\ Section of Neurobiology and Behavior \\ Cornell University, Ithaca, NY 14853
}

On August 3, 1984, in the course of field work near Portal, Highlands County, Arizona, I caught sight of a gaudily-colored tephritid fly, which at first completely fooled me into believing it was a jumping spider. Subsequently caught and identified as Zonosemata vittigera, it had been resting on a leaf of its larval food plant (Cazier, 1962), the white horse nettle Solanum elaeagnifolium. Rather than taking instantly to flight in response to my approach, it moved about erratically over the leaf, or in short darting flights from leaf to neighboring leaf, in patent imitation of the close-range evasive maneuverings of jumping spiders. What made the mimicry uncanny was the fly's seeming predilection during moments of rest of presenting itself in rear-end view (Fig. 1). Thus oriented, with its abdomen masquerading as a prosoma (complete with eye spots), its thorax plus head as an opisthosoma, and the dark bands on its wings as a set of legs, it took on a distinct spider-like appearance. The overall aposematism, so characteristic of jumping spiders, completed the imitation. The fly's abdomen is orange (evenly colored, like many a jumping spider's prosoma), and its thorax yellow and black (mottled, like many an opisthosoma). Its actual legs, irrelevant to the mimicry and potentially distractive from the resemblance, are yellowish-green, in line with the background vegetation. Subsequent sightings that I made of the fly were on both $S$. elaeagnifolium and on sunflower (Helianthus annuus).

Imitation of jumping spiders could clearly be of benefit to an insect. Jumping spiders are hard to catch and capable of inflicting poisonous bites, and might thus be shunned by any number of vertebrate and insectan predators.

Other tephritids may show comparable mimicry. Monteith (1972) pointed to the similarity in appearance and movement of Rhagoletis pomonella to the sympatric jumping spider Paraphidippus margina-

*Manuscript received by the editor September 2, 1984 


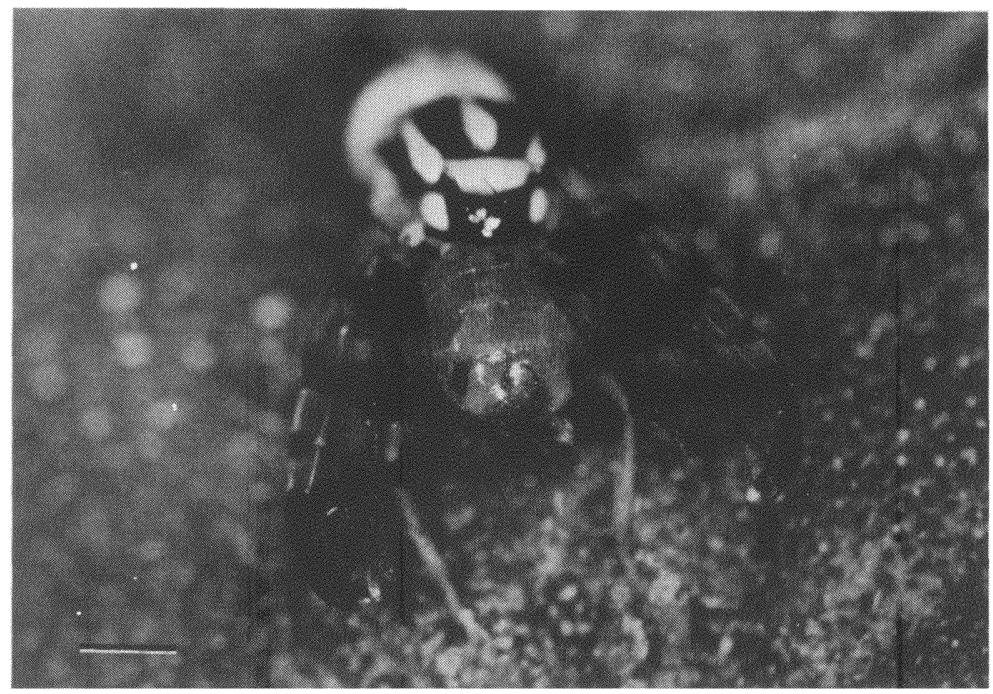

Figure 1. Zonesemata vittigera, in rear-end view. Note resemblance to jumping spider in frontal view. For purposes of photography, the animal was briefly cooled by refrigeration. (Reference bar $=1 \mathrm{~mm}$ )

tus. Guy L. Bush (personal communication) suggests that other Rhagoletis of the pomonella species group, including $R$. mendax, $R$. zephyria, and $R$. cornivora, may be similarly mimetic, and that jumping spider mimicry may have arisen independently in other tephritid lineages as well.

\section{ACKNOWLEDGEMENT}

I thank David Grimaldi for confirming the identification and for bibliographic help, and R. J. Prokopy for calling to my attention the Monteith reference.

\section{RHFiRENC'S CITED}

CAZII:R, M. A.

1962. Notes on the bionomics of Zonesemata vittigera (Coquillett), a fruit fly on Solanum (Diptera: Tephritidae). Pan-Pacific Entomologist 38: $181-186$.

Monteith, L. G.

1972. Status of predators of the adult apple maggot, Rhagoletis pomonella, in Ontario. Can. Entomol. 104: 257-262. 

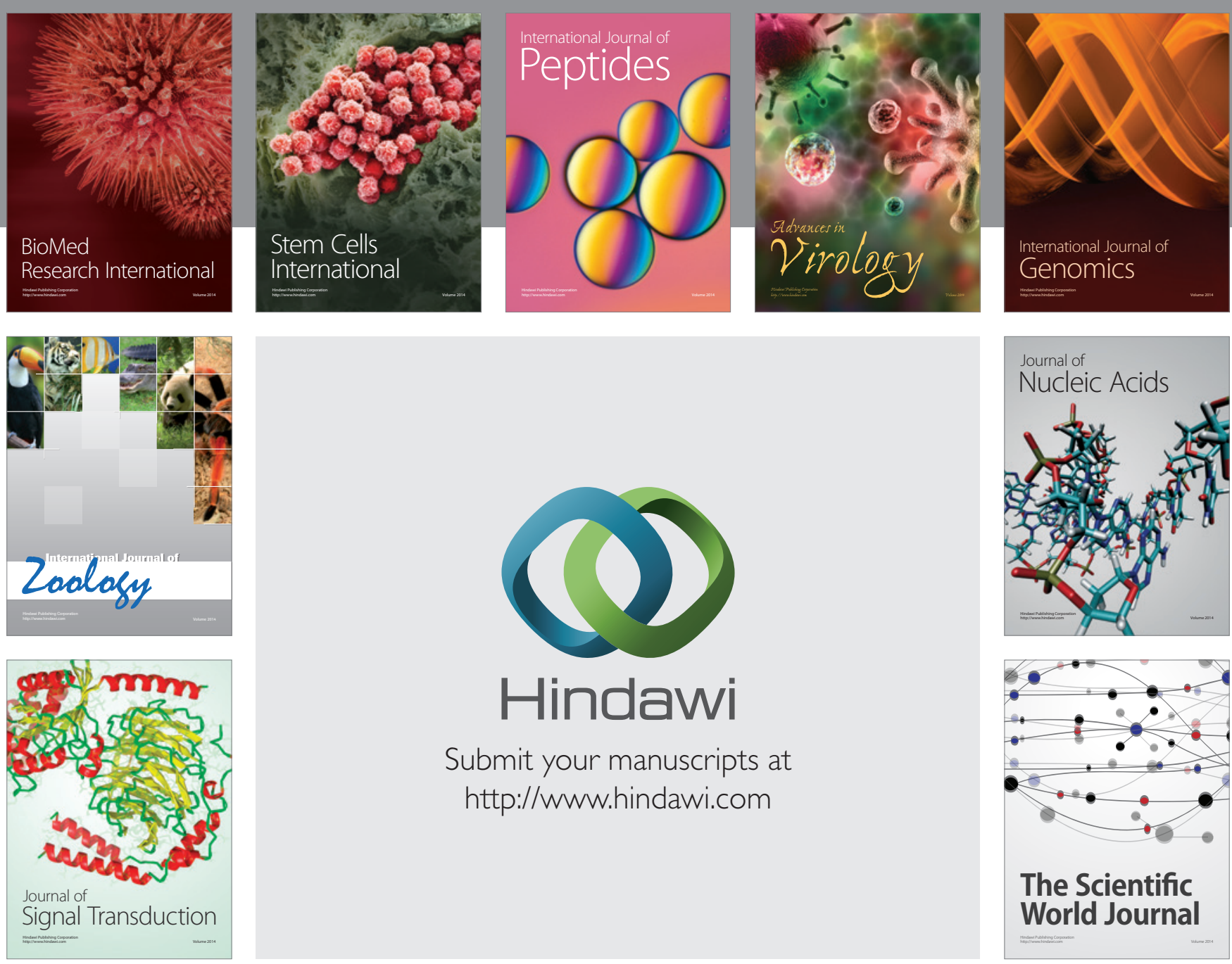

Submit your manuscripts at

http://www.hindawi.com
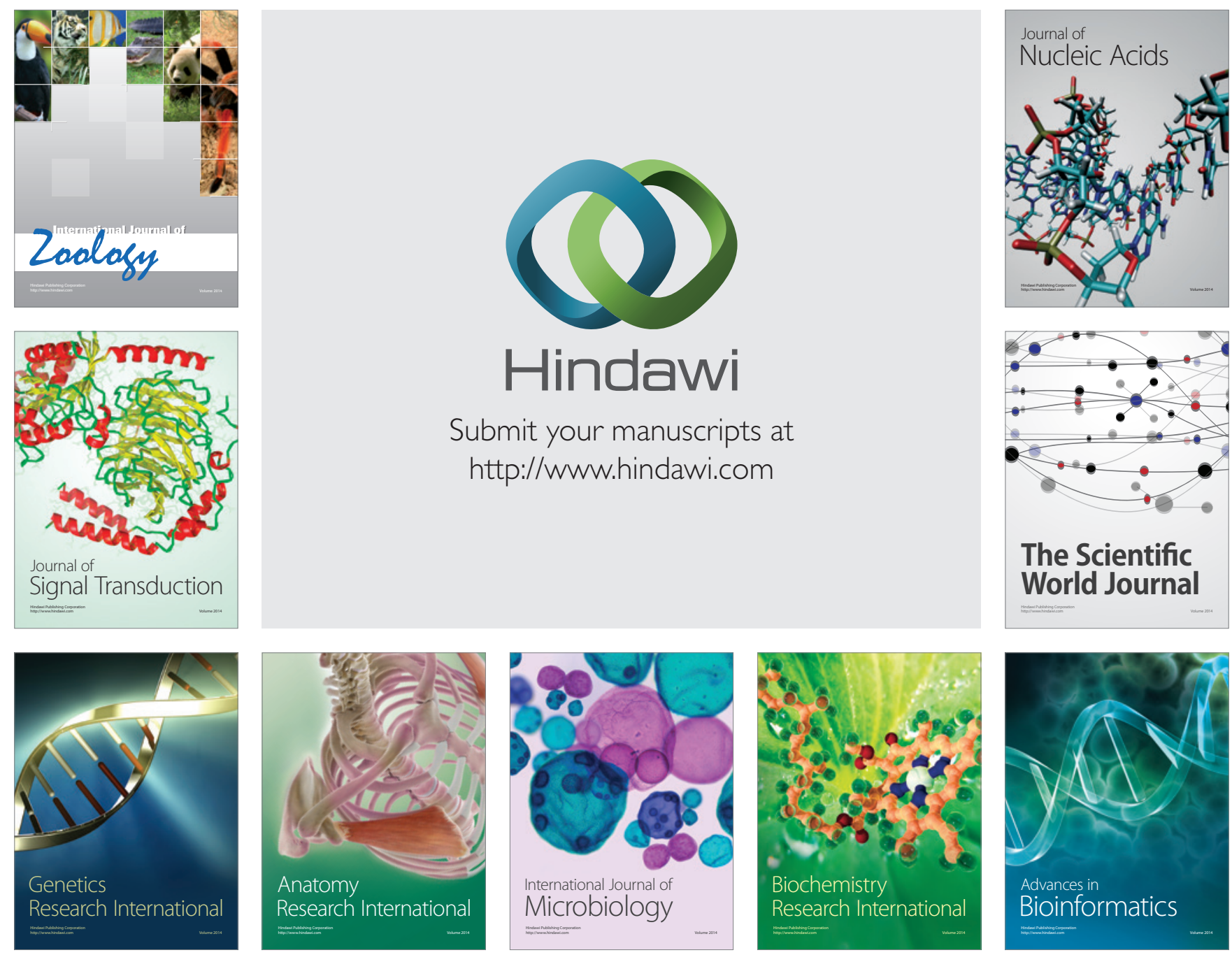

The Scientific World Journal
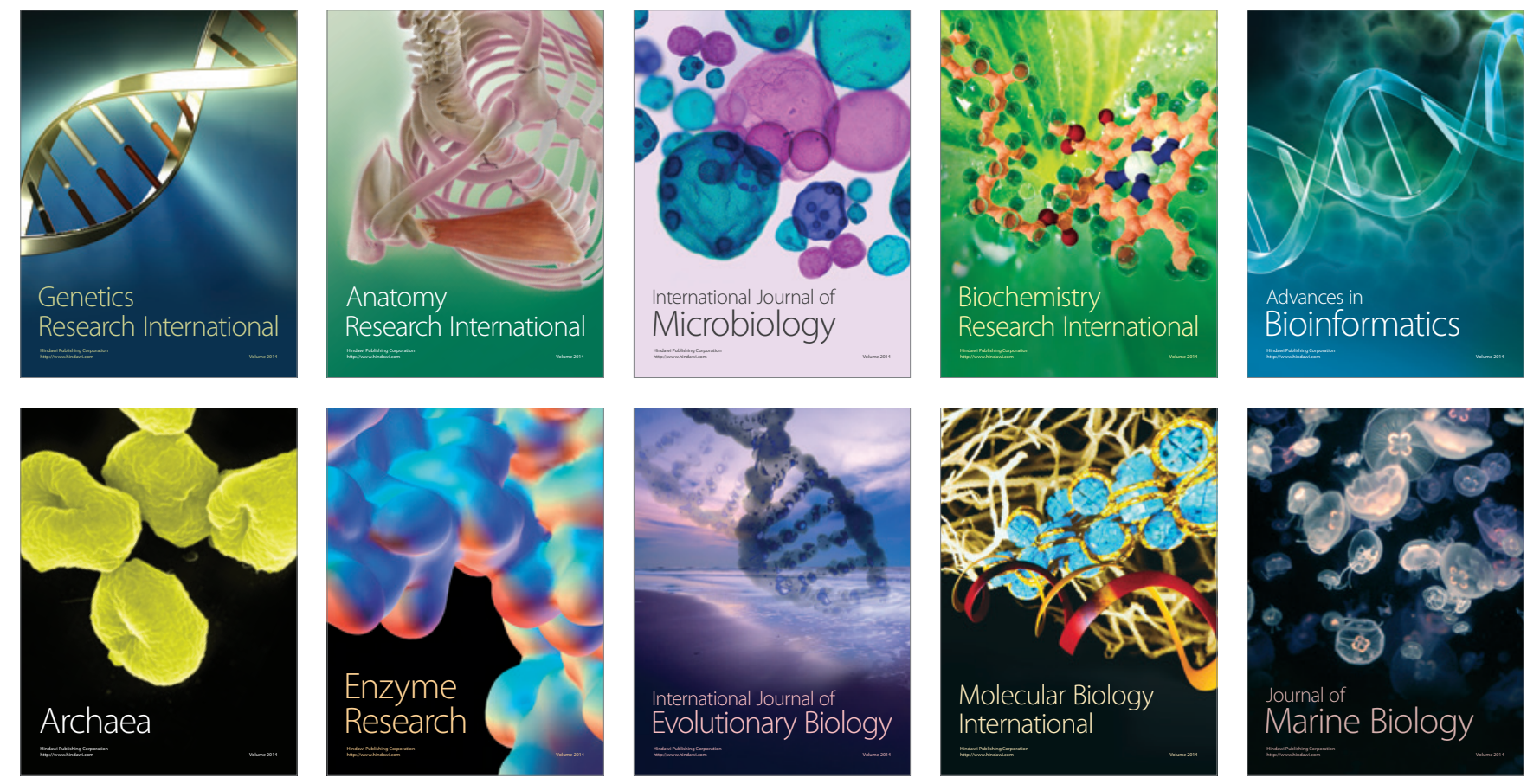